\title{
SORRISO: UM INDICADOR DE FELICIDADE
}

\section{THE SMILE: AN INDICATOR OF HAPPINESS}

Paula Inez Cunha Gomide ${ }^{1}$

GOMIDE. P. I. C. Sorriso um indicador de Felicidade. Rev. Bras. Cresc. Desenv. Hum. São Paulo 6 (1/2). 1996.

\begin{abstract}
Resumo: Este trabalho visou analisar os efeitos da institucionalizacão OU da vida familiar no sorriso de crianças e adolescentes. O homem passeai itll repertório universal de movimentos expressivos clive permite a comunicação a despeito de barreiras culturais e lin^ouisticas. Pesquisadores de expressão facial verificaram que o sorriso é urna poderosa fonte de recompensas interpessoais e está ligado ao estado emocional de alegria. Os ort ‘anatos, as favelas e os ambientes familiares variam em graus de sorrisos dispensados e correspondidos. Dois e ; perimentos foram realizados para investigação da hipótese acima. O experimento I registrou sorrisos em criancas de ambos os sexos. com idade variando entre 5 e 10 anos. provenientes de um orfanato, de uma favela e de um bairro de classe média. O experimento 11 observou adolescentes de 14 a 21 anos, sexo masculino, oriundos de um internato para adolescentes infratores; de rim semiinternato para adolescentes infratores e de uma instituição educacional de À grau. Os sujeitos eram observados em situação de brincadeira. Verificou-se, claramente, que as crianças e os adolescentes insti^htcionalizados sorriam significativamente menos que aquelas que estavam em liberdade, mesmo que em condições económicas mais precárias, como as da favela. Esta pesquisa indica que as instituições que isolam as crianças e adolescentes de suas famílias prejudicam fortemente o seu desenvolvimento afetivo e sua felicidade.
\end{abstract}

Palavras-chave: sorriso criança, adolescente, institucionalização.

\section{INTRODUÇÃO}

Desde os primeiros dias do seu nascimento, o bebê assume um papel ativo em sua interação com o mundo externo. Com pouca competência motora tem, no entanto, sistemas de sinalização social muito eficientes que asseguram a proximidade das pessoas que cuidam e com ele interagem. Segundo DARWIN (1872), o sorriso é um dos sinais mais poderosos da espécie humana pelo seu alto valor de sobrevivência, pois produz a aproximação da mãe e a mantém próxima à criança. $\mathrm{O}$ sorriso do bebê gera alegria no adulto, que conversa mais com ele atende melhor às suas necessidades de fome, conforto, frio, etc. Sendo o bebê totalmente indefeso e dependente tem no sorriso um instrumento poderoso de aproximação e manutenção do adulto junto a si. Além do sorriso, as próprias características estruturais do rosto e do corpo do bebê são estímulos capazes de desencadear sentimentos ternos e protetores nos adultos (EIBSFELDT, 1970).

Nas três primeiras semanas de vida o sorriso ainda não é usado propositadamente para obter atenção, esta fase é denominada de espontânea ou reflexa. Os sorrisos desta fase tendem a ocorrer durante os estados de sono de movimentos oculares rápidos (estados IRM). Observou-se também que eles aparecem com maior freqüência entre as crianças prematuras quando comparadas com as normais. Os sorrisos não-eliciados tendem a desaparecer por volta da terceira semana, quando então observa-se o aparecimento dos primeiros sorrisos verdadeiros. Entre o final do primeiro mes e o terceiro mes os bebês começam a olhar nos olhos das pessoas que interagem com eles. Ocorrem mudanças no sorriso, que passa de fugidio e aparentemente controlado por tutores

1 Psicóloga. Profa. Dra. do Departamento de Psicologia da Universidade Federal do Paraná.

End.: R. Bruno Filgueiras, 2100 apto 79. Champagnat. Curitiba - PR. CEP: 80.430-380. Tel.: (041) 335-1254. 
intemos a um sorriso completo e reconhecido, produzido principalmente pela visão da face humana (OTTA, 1994).

Até cinco meses o bebê responde igualmente ao rosto de uma pessoa sorridente. carrancuda ou que está chorando. Daí em diante passa a diferenciar as pessoas entre si. Nas primeiras semanas eles respondem automaticamente às pessoas independentemente do grau de familiaridade. Sorriem quase que imediatatnente para uma pessoa estranha e não apresentam sinais de Consciência da falta de familiaridade. Entre três e cinco meses a resposta passa a ser seletiva. Enquanto a mãe continua provocando sorrisos imediatos, uma pessoa estranha é recebida com o rosto sério, desconfiado. Com oito meses ocorre outra mudança signiticativa: o bebê além de olhar finamente, com o rosto sério, para pessoas nãofamiliarcs, passa também a apresentar sinais de medo. O fenômeno é conhecido como ansiedade dos oito meses. O bebê deixa de tratar todos igualmente, passa a reagir de forma seletiva, sorri para a mãe e outros familiares e chora para estranhos (OTTA, 1994).

De maneira que, a partir desta idade, quando uma pessoa aproxima-se de um bebé, este poderá reagir abrindo um largo sorriso, estendendo os bracinhos ou poderá permanecer sério, olhando fixamente para a recém-chegada. As duas reações distintas correspondem, por um lado, ao grau de familiaridade, pessoas familiares são saudadas com alegria, desconhecidos com desconfiaça ou, por outro lado, a reação poderá ser em função da aparência do adulto, ou seja, adultos com aparência incomum (muita barba ou cabelo muito alto, cabelos com tons fortes, etc.) podem desencadear choro e espanto no bebê. Recentemente, seguranças em um Shopping Center de São Paulo apresentaram uma estatística de que 3 , em cada 10 crianças. choravam ao ver Papai Noel (OTTA, 1994).

Comparativamente. sabe-se meios sobre o desenvolvimento do riso que do sorriso. Ele aparece por volta dos quatro meses de idade, mais tardiamente portanto que o sorriso (OTTA, 1994). Iniciahnente, os desencadeadores mais efetivos são estímulos básicos vigorosos (cócegas. por ex.); mais tarde. a eficácia destes estímulos diminue e o riso passa a ser desencadeado por estímulos que contêm elementos de incongruência cognitiva, como por exemplo, ver a mãe fazer de conta que toma mamadeira. O riso é visto como um comportamento que, ao mesmo tempo, promove e repete o desenvolvimento cognitivo. Com o passar dos meses o bebê ri mais, quanto mais participa ativamente da brincadeira, ou seja, quando finge alimentar a mãe e retira o alimento na hora em que ela está pronta para fechar a boca. Segundo
LORENZ (1966), o riso desenvolveu-se provavelmente por ritualização. a partir de um movimento de ameaça reorientado e tem o efeito de fazer imediatamente nascer entre os participantes um forte sentimento de camaradagem, associado a uma ponta de agressividade, contra os que não fazem parte do grupo.

Ao chorar, um bebê tende a se afastar do estímulo, mas rindo, mantém uma orientação positiva em relação a ele. A situação de estímulo que provocou estas duas reações é uma situação de estímulos discrepantes, daí se admitir que quando o bebê ri a mãe reapresenta o estímulo, aumentando as oportunidades de contato com experiências novas. Do ponto de vista adaptativo parece interessante que o organismo em desenvolvimento disponha de mecanismos para lidar com aspectos novos e provocativos do ambiente. $\mathrm{O}$ riso, aparentemente uma atividade biologicamente supérflua, transforma-se num mecanismo importante e necessário para promover desenvolvimento cognitivo e emocional (OTTA. 1994).

De acordo com a definição de BRANNIGAN \& HUMPHRIES (1972) o comportamento de sorir refere-se à curvatura da boca para cima, com os lábios fechados ou exibindo a dentição. Os sorrisos apresentam diferentes topografias. Pode-se diferenciar o sorriso em: fechado, sem exposição dos dentes, superior ou semi-aberto, com exposição dos dentes superiores e largo ou aberto, com exposição dos dentes superiores e inferiores (CHEYNE, 1976). OTTA \& SARRA (1989) pesquisando tipos de sorriso espontâneo em pré-escolares encontraram correlação negativa entre o sorriso fechado e o superior, ou seja, as crianças que apresentavam muito determinada topografia de sorriso apresentavam pouco a outra. Além disso encontraram correlação positiva entre sorriso largo e riso, ou seja, as crianças que exibiam muito uma forma de expressão também o faziam com a outra. As autoras sugerem que o padrão de correlações encontrado indica que o sorriso é uma categoria motivacional heterogênea, além de ser heterogêneo do ponto de vista da forma. A análise de contexto feita pelas autoras aponta que o sorriso fechado ocorria predominantemente quando a criança estava sozinha ou observando cenas sociais, sem estar diretamente envolvida nelas; ou então quando recebia uma crítica ou um elogio de um adulto e ficava aparentemente sem graça. O sorriso superior ocorreu na maioria das interações envolvendo cumprimentos, mostrar oferecer, pedir e dar objetos, comentários, propostas, perguntas e chamados. O sorriso largo e o riso ocorriam tipicamente durante brincadeiras motoras amplas, que incluiam correr e outras formas de locomoção incomuns (an- 
dar sentado, agachado, etc) e também em brincadeiras turbulentas de contato físico intenso. Esta análise das autoras sugere que as várias modalidades de expressão podem ter funções comunicativas diferentes.

\section{MOVIMENTOS EXPRESSIVOS E SENTIMENTOS}

O homem possui um repertório universal de movimentos expressivos que permite a comunicação a despeito de barreiras culturais e lingüísticas. Os movimentos expressivos estão associados aos estados emocionais: alegria, tristeza, surpresa, raiva, medo e nojo. Através de sua exibição os outros são capazes de inferir a emoção sentida por uma pessoa e o seu comportamento futuro. A expressão das emoções, segundo DARWIN (1872), é essencial para a vida, pois tal expressão comunica como o indivíduo, seja ele homem ou animal, se sente e contribui para a regulação das interações sociais. Entre os movimentos inatos arrolados por Darwin estão o sorriso e o riso, que além de universais, aparecem em indivíduos cegos que não poderiam aprendê-los por imitação (EIBSFELDT, 1970).

VAN HOOF (1972) detendo a tese de que o sorriso esteja ligado evolucionariamente à exibição silenciosa dos dentes e que teria a função de atenuar o comportamento hostil dos animais dominantes, BLURTON JONES (1972), por sua vez, sugere que o sorriso humano faz parte de um ritual de apaziguamento e FAGUNDES (1976) propõe que o sorriso humano, além das funções redutoras de hostilidade, permite a manutenção do contato amistoso.

No entanto, apesar do seu caráter inato o sorriso e o riso podem ser afetados pelo ambiente. GEWIRTZ (1965) estudou em Israel a influência de diferentes ambientes no desenvolvimento do sorriso. O autor comparou o comportamento de sorrir de bebês nos primeiros 18 meses de vida em quatro ambientes: creche, instituição família e kibutz. Os resultados mostraram que crianças criadas em famílias sorriam muito mais do que as criadas em Kibutz e estas mais do que as criadas em creches e em instituições. Não houve diferença entre o nível de sorriso das crianças da creche quando comparadas às de instituições. Estas diferenças poderão ser devidas à disponibilidade de estímulos evocadores de sorriso existentes nos vários ambientes. Se o sorriso do bebê é acompanhado por expressões carinhosas e carícias sua taxa aumenta, caso seja seguido por uma expressão neutra a taxa diminue até extinguir-se (BRACKBILL, 1958, apud OTTA, 1994).
As expressões faciais podem ter diferentes efeitos em diferentes culturas. Crianças sorridentes são em culturas que valorizam positivamente o sorriso, de modo geral, percebidas como mais competentes socialmente que as não sorridentes. Com a socialização as crianças aprendem a monitorar e a regular os seus comportamentos expressivos. Não somente reagem às situações espontaneamente como também começam a avaliar o contexto interpessoal associado à situação aliciadora da emoção e a controlar seus comportamentos expressivos de acordo com esta avaliação. O povo japonês apresenta o sorriso do tipo semi-aberto ou sorriso amarelo em situações de constrangimento, provavelmente para encobertas a verdadeira emoção - a vergonha - pois a cultura japonesa pune severamente o fracasso.

Pesquisadores de expressão facial (ARGYLE, 1988; TIDD \& LOCKARD, 1978; LAU, 1982; DION et al., 1972; FORGAS et al.; apud OTTA, 1994) verificaram que o sorriso é uma poderosa fonte de recompensas interpessoais. A pessoa sorridente é percebida, de modo geral como mais bonita alegre, simpática, bondosa, sincera competente, sociável e inteligente. No entanto, estas características podem alterar-se em função do sexo, idade e tipo de sorriso, se fechado, superior ou largo.

Observações feitas por BLURTON JONES (1972) com pré-escolares indicam que o sorriso humano pode ser visto como parte de um ritual de apaziguamento. $\mathrm{O}$ autor encontrou correlação entre dominância e sorrir. Crianças de baixo posto hierárquico sorriem mais quando iniciam interação com outras de alto posto do que estas quando interagem com as de baixo posto hierárquico. Muitos estudos mostram que, em várias situações mulheres sorriem mais do que homens (OTTA et al. 1992). E as mães de classe média sorriem significativamente mais do que as de classe baixa (BUGENTAL et al., 1970).

O sorriso pode ser uma expressão genuína de prazer, que sinaliza empatia e abertura para interação verbal, mas pode estar associado a tensão e desconforto.

De todas as expressões faciais de afeto, talvez o sorriso seja uma das mais simples e mais facilmente reconhecida. Apenas um músculo da face - o zygomatic major - é necessário para produzi-lo, enquanto as expressões de raiva, medo e tristeza requerem a ação de dois ou quatro músculos independentes. É muito mais facilmente reconhecida do que outras expressões a grandes distâncias ou quando o tempo de exposição é limitado a apenas uma fração de segundo.

No entanto, a despeito da facilidade de produção e de reconhecimento, o sorriso pode gerar 
considerável confusão de interpretação, uma vez que é exibido:

a) quando algo nos agrada genuinamente; b) como um sinal de deferência ou polidez e c) quando estamos aflitos ou amendrontados (BUGENTAL et al. 1970). Será possível diferenciar um sorriso verdadeiro de um falso? Segundo GOFFMAN (1979) e KRAUT (1978) ao pesquisarem o princípio da autoconsciência e da controlabilidade é mais fácil acreditar em comportamentos que são mais difíceis de controlar. Levando-se em conta que temos mais consciência das reações do rosto do que de outras partes do corpo uma das principais dificuldades em identificarmos sinais de veracidade ou não do sorriso está no fato de mentirmos melhor com a face do que com outras partes do corpo.

Diferenças sutis entre formas de sorriso permitem distinguir quando as pessoas estão sendo autênticas ou quando estão mentindo e mascarando sentimentos negativos. Pode-se dizer que as pessoas sorriem com os lábios e também com os olhos quando sua alegria é autêntica. Por outro lado, sorrisos que incluam traços de ações musculares associadas a nojo, medo desprezo ou tristeza ocorrem mais freqüentemente durante a apresentação do sorriso mascarado.

O sorriso falso e do tipo acende-apaga. $\mathrm{O}$ tempo de aparecimento e desaparecimento do sorriso é outro indício de sua veracidade. O sorriso falso aparece muito rápido no rosto imóvel e desaparece com igual rapidez. O sorriso verdadeiro leva mais tempo para se instalar no rosto e depois para desaparecer. A falta de reciprocidade na interação produz sorrisos que são abortados.

O sorriso falso pode apresentar defeitos de intensidade: versão amortecida e versão exagerada ou então eles são assimétricos em comparação com o sorriso verdadeiro que é simétrico, ou seja, podem apresentar-se mais fortes em uma das faces.

Em resumo, o sorriso verdadeiro apresenta-se simétrico com rugas do tipo pés-de- galinha em torno dos olhos; tem expressão pura de alegria; tem início longo e desvanecimento longo. Já o sorriso falso é assimétrico, não havendo rugas em torno dos olhos; tem expressões mistas, indiscrições não-verbais; é do tipo acende-apaga e tem alterações de intensidade de amortecimento e exagero (OTTA, 1994).

De acordo com CHEVALIER SKOLNIKOFF (1973), no homem, o contínuo sorriso-riso tem uma função geral e expressa intenções positivas. $\mathrm{O}$ que sugere que intenções positivas estejam relacionadas com bem-estar do organismo. Naturalmente, estes indicadores permitem a escolha do sorriso como uma expressão facial que repete, prioritariamente, felicidade.
Esta pesquisa foi elaborada para avaliar a influência dos ambientes: orfanatos, favelas e ambiente familiar de classe média, no nível de sorriso de crianças e adolescentes. Os orfanatos, as favelas e os ambientes familiares variam, ao que se sabe, em graus de estimulação, afeto dispensado às crianças, atenção, liberdade de ir e vir, verbalização e, principalmente, de sorrisos dispensados e correspondidos. Pode-se supor que estas variáveis sejam responsáveis por uma série de diferenças entre estes grupos de crianças. Neste trabalho no entanto, estaremos investigando somente as diferenças, se houverem no nível de sorriso destas crianças e adolescentes. Dois experimentos foram realizados para avaliação desta hipótese. O experimento I com crianças de 5 a 10 anos de idade e o Experimento II com adolescentes.

\section{METODO}

\section{Experimento I}

Sujeitos: Participaram deste experimento 60 crianças. de ambos os sexos. com idades entre 5 e 10 anos. Os sujeitos eram provenientes de três ambientes distintos: 20 crianças pertenciam a um orfanato, somente para meninos. que oferecia boas condições alimentares e de moradia; 20 moravam em uma favela da cidade de Curitiba ( 13 meninos e 7 meninas) e 20 residiam com suas famílias, em um prédio num bairro de classe média da cidade (11 meninos e 9 meninas).

Proceclimento: Os dados foram coletados através do registro a intervalos de tempo, em intervalos de 10 segundos. Neste tipo de registro o observador anota na casela se ocorreu ou não o comportamento, independentemente da freqüência de ocorrência. Cada sujeito foi observado durante seis minutos. de forma intercalada, ou seja, o sujeito número 1 era observado durante 1 minuto e depois seria observado novamente após a observação do vigésimo sujeito. isto é, no vigésimo primeiro minutos e assim por diante. A sessão durava 120 minutos. Dois observadores registravam a intervalos de 10 segundos, para cada sujeito, a ocorrência ou não do comportamento de sorrir. Sorriso foi definido como a retração dos cantos da boca, para cima, com ou sem exposição dos dentes. Situação observacional. Todas as crianças foram observadas em situação de brincadeira livre. As crianças da instituição estavam no playground e na cancha de esportes; as da favela estavam jogando bola num pequeno campo de terra contendo duas traves; as do prédio de classe média brincavam no playground do prédio. 


\section{Experimento II}

Sujeitos: Foram observados 24 adolescentes, do sexo masculino, formando três grupos de 8 sujeitos cada. com idade variando de 14 a 21 anos, oriundos de três instituições, a saber: a) internato para adolescentes infratores; b) semi-internato para adolescentes infratores cumprindo medida socioeducativa de semiliberdade; c) colégio, ou seja, instituição educacional de $1^{\circ}$ e $2^{\circ}$ graus.

Procedimento: Os dados foram coletados através do registro de amostragem de tempo, em intervalos de 10 segundos. Cada sujeito foi observado durante sete minutos. de forma intercalada, ou sejas o sujeito número 1 era observado durante 1 minuto e depois seria observado novamente após a observação do oitavo sujeito, isto é. no nono minuto, e assim por diante. A sessão durava 56 minutos. Os observadores registravam a intervalos de 10 segundos, para cada sujeito, a ocorrência ou não do comportamento de sorrir. O comportamento de sorrir foi subdividido em três tipos: sorriso fechado (sem o aparecimento dos dentes e com 1 retração dos cantos da boca para cima); sorriso semi-aberto (com exposição da fileira superior dos dentes) e sorriso aberto (com exposição das duas fileiras de dentes). Foram registrados também a não possibilidade de observação (quando o sujeito estava de costas por exemplo).

Situação observacional: Os sujeitos do colégio foram observados na cancha de esportes da escola jogando futebol; quatro observadores registraram os dados. Os sujeitos do semi-internato foram observados no salão de jogos da unidade. que continha mesa de pingue-pongue, de pebolim e de sinuca; três observadores registraram os dados. Os sujeitos do internato foram observados na cancha de esportes da instituição jogando basquete; três observadores registraram os dados. Após as observações foram calculados os índices de fidedignidade entre observadores.

\section{RESULTADOS}

\section{Experimento I}

Apesar de haver indicadores na literatura de uma diferença na freqüência de sorriso entre sexos (OTTA, 1994) os dados revelados no Experimento I não constataram esta diferença. No grupo de crianças da Favela, a média de sorriso dos meninos ficou em $13,04 \%$ e das meninas 11,71 \%; entre as crianças do Prédio a média masculina ficou em torno de $12,09 \%$ e a feminina em $13,40 \%$. As diferenças foram pequenas e se alter- naram de um grupo para outro. A instituição era composta somente de meninos impossibilitando este tipo de análise.

Uma análise de variancia foi realizada para verificar se as diferenças encontradas entre os percentuais de sorriso nos grupos de crianças eram estatisticarnente significativas. A comparação entre as crianças da Favela com as crianças do Prédio não foi significativa $(\mathrm{F}=0,001)$; já quando se compararam os dados das crianças da Instituição com as da Favela $(F=9,55)$ e Instituição e Prédio $(\mathrm{F}=2 \mathrm{l}, 27)$ ambos mostraram-se significativos no nível de $0,01 \%$. Os dados indicam, portanto, que as crianças da Favela sorriem tanto quanto as crianças do Prédio de classe média, e que estes dois grupos sorriem significativamente mais que as crianças da Instituição.

Tabela 1. Percentagem de sorriso dos sujeitos em cada local de observação.

\begin{tabular}{cccc}
\hline Sujeito & Instituição & Favela & Prédio \\
\hline 01 & 17 & 33 & 36 \\
02 & 44 & 30 & 39 \\
03 & 25 & 72 & 39 \\
04 & 28 & 33 & 44 \\
05 & 17 & 28 & 47 \\
06 & 08 & 36 & 19 \\
07 & 00 & 47 & 61 \\
08 & 14 & 05 & 33 \\
09 & 25 & 44 & 33 \\
10 & 14 & 50 & 39 \\
11 & 17 & 36 & 42 \\
12 & 17 & 39 & 36 \\
13 & 19 & 25 & 44 \\
14 & 33 & 08 & 30 \\
15 & 28 & 05 & 28 \\
16 & 22 & 50 & 25 \\
17 & 30 & 50 & 30 \\
18 & 30 & 55 & 19 \\
19 & 11 & 19 & 25 \\
20 & 14 & 17 & 33 \\
\hline
\end{tabular}

A tabela 1 mostra os percentuais de sorrisos, em minutos, das 20 crianças observadas em cada um dos três ambientes.

A figura 1 mostra graficamente as médias dos percentuais de sorriso de cada grupo pesquisado. Verifica-se claramente que a média de sorriso das crianças da Instituição (X = 20,65) é bem inferior às das crianças da Favela 
$(X=34,95)$ e do Prédio $(X=35,15)$. Estes dados apontam para o flato de que, crianças mesmo sem boas condições materiais, como as da favela, mas que mantêm relações familiares, sorriem mais que crianças institucionalizadas, sendo, portanto, sugestivos de uma vida social e afetiva mais significativa e indicadores potenciais de mais felicidade. A análise do desvio padrão dos grupos mostra que o maior está entre as crianças da Favela (S = 18,13), apontando uma maior diversidade entre os sujeitos, ou seja, aparentemente, as condições de vida das famílias apresentam uma variabilidade muito grande de interação. As crianças da Instituição $(S=9,97)$ e do Prédio $(S=9,92)$ apresentam uma amostra mais homogênea indicando uma situação ambiental mais estável, o que era de se esperar.

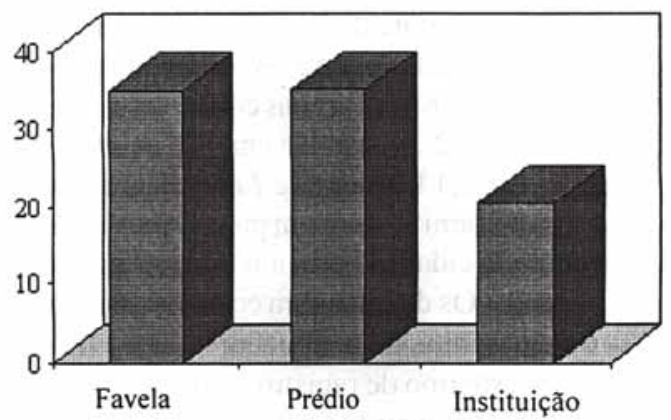

Figura 1. Sorriso em crianças

De acordo com SPITZ ( 1991), o sorriso é um bom indicador de felicidade pois aparece nas crianças espontaneamente e demonstra a existência de um bom vínculo afetivo entre a mãe (ou quem desempenhe este papel) e a criança. Este vínculo afetivo satisfatório seria a base para um bom desenvolvimento emocional e para a possibilidade de felicidade. Nossos dados indicam que as crianças institucionalizadas sorriem menos. A literatura aponta que um índice pequeno de sorriso correlaciona-se com um menor grau de felicidade.

\section{Experimento II}

O segundo experimento foi realizado com o objetivo de verificar se os resultados obtidas com crianças também eram encontrados com adolescentes. Neste experimento utilizaram-se unicamente sujeitos do sexo masculino impossibilitando, portanto, qualquer comparação entre sexos. A figura 2, mostra as médias de sorriso encontradas nos três grupos pesquisados. Os adolescentes do Colégio apresentaram uma média de sorriso de $45,13 \%$, os do Semi-internato de $28,56 \%$ e os do Internato de 19,79\%.
Mais uma vez os dados vêm ao encontro da hipótese formulada neste trabalho: situações de isolamento social são imcompatíveis com estado de felicidade. Os adolescentes infratores submetidos à medida socioeducativa de privação de liberdade sorriem menos da metade do tempo que adolescentes do colégio. Alguns poderiam argumentar que este fato é decorrente da história de vida destes garotos, no entanto, observa-se que adolescentes infratores submetidos à medida socioeducativa de semi-liberdade apresentam índices de sorriso bem mais próximos aos dos garotos do colégio.

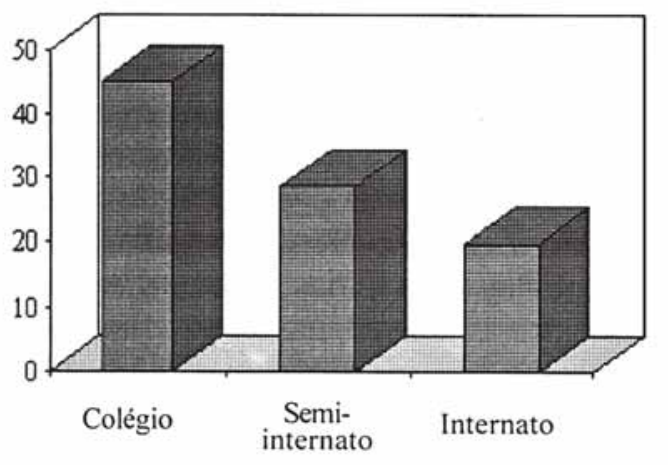

Figura 2. Média do seorriso em adolescentes

No experimento II foram registrados três tipos de sorriso: Aberto, Fechado e Semi-aberto. Estes dados foram analisados separadamente como podem ser vistos na figura 3. Os dados do Sorriso Aberto (com exposição das duas fileiras de dentes) apresentaram resultados muito semelhantes às médias do sorriso, quando se considera o comportamento de sorrir de forma unitária, ou seja, contendo os três tipos de sorriso. Este tipo de sorriso é considerado o mais espontâneo, muitas vezes confundido com o riso. Os adolescentes do Colégio apresentaram uma média de Sorriso Aberto igual a 25,69\%, os do Semi-internato de $17,26 \%$ e os do Internato de 4,26\%. Analisando-se os dados refentes ao Sorriso Fechado (sem exposição de dentes) pode-se observar que os adolescentes apresentaram uma taxa bem inferior a do Sorriso Aberto, ou seja, os adolescentes do Colégio sorriram em média 7,63\% do tempo, os de Semi-internato, 6,54\% e os do Internato apenas $1,38 \%$ do tempo de observação.

Uma análise mais cuidadosa dos índices médios de Sorriso Semi-aberto aponta para algumas reflexões curiosas. Os adolescentes do Colégio apresentaram uma taxa de $11,80 \%$, os do Semiinternato de 4,76\% e os do Internato de 13,54\%. Neste tipo de sorriso os adolescentes infratores presos apresentaram uma taxa média de sorriso 


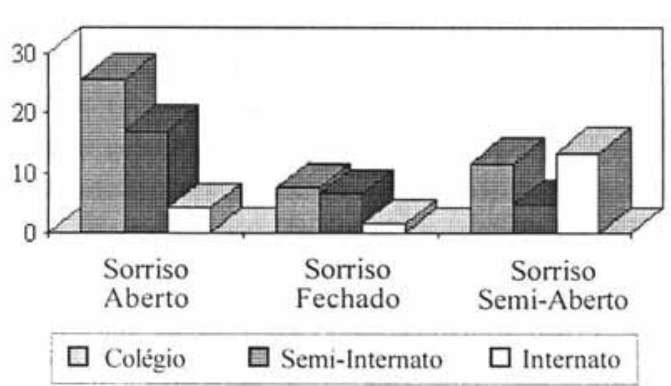

Figura 3. Sorriso Aberto, Fechado e Semi-Aberto em Adolescentes

maior que a dos outros dois grupos. Análises deste tipo de sorriso apontam para o fato de que este é um sorriso comumente apresentado em situações de constrangimento ou falsidade, sendo também denominado de Sorriso Falso, quando assimétrico, feito exclusivamente pela boca, sem acompanhamento das rugas dos olhos e, aparecendo e sumindo rapidamente (OTTA, $1994 \mathrm{p}$. 101). O Sorriso Aberto ou Largo, com a apresentação das duas fileiras de dentes é mais difícil de ser simulado, já o Sorriso Semi-Aberto está mais relacionado com o tipo de sorriso amarelo, termo este utilizado para se referir ao sorriso que pretende encobrir os reais sentimentos. Deste modo, uma investigação futura poderia analisar qualitativamente o sorriso Semi-aberto para avaliar esta hipótese.

A tabela 2 mostra os resultados obtidos através da análise de variância calculada para a comparação entre grupos de adolescentes e de tipos de sorriso. Considerou-se: Grupo 1 a comparação entre Colégio X Semi-internato: Grupo 2 Colégio X internato e Grupo 3 Semi-internato X internato. Foram realizadas comparações também entre os três grupos de adolescentes para cada um dos tipos de sorriso e para a somatório dos sorrisos.

Tabela 2. Análise de comparação entre grupos de adolescentes e de tipos ele sorriso e da somatório total de sorrisos.

Tipos de Sorriso

\begin{tabular}{ccccc}
\hline Grupo & Fechado & Semi-aberto & Aberto & Total \\
\hline 1 & $\mathrm{~F}=2,28(\mathrm{p}=0,64)$ & $\mathrm{F}=14,21(\mathrm{p}=0,001)^{*}$ & $\mathrm{~F}=1,746(\mathrm{p}=0,2075)$ & $\mathrm{F}=6,78^{*}$ \\
2 & $\mathrm{~F}=14,90(\mathrm{p}=0,001)^{*}$ & $\mathrm{~F}=0,13(\mathrm{p}=0.73)$ & $\mathrm{F}=0,21(\mathrm{p}=0,0005) *$ & $\mathrm{~F}=8,78^{*}$ \\
3 & $\mathrm{~F}=18,62(\mathrm{p}=0,0007)^{*}$ & $\mathrm{~F}=9,13(\mathrm{p}=0,001)^{*}$ & $\mathrm{~F}=13,47(\mathrm{p}=0,0004)^{*}$ & $\mathrm{~F}=1,167$ \\
\hline
\end{tabular}

* Índices significativos estatisticamente

Quando se comparou Colégio, Semi-internato e Internato o resultado para o Sorriso Fechado foi $\mathrm{F}=9,13(\mathrm{p}=0,001)^{*}$; no caso do Sorriso Semi-abérto obteve-se $\mathrm{F}=2,347(\mathrm{p}=0,1202)$; para o Sorriso Aberto obteve-se $\mathrm{F}=11,161$ $(p=0,0004 \wedge) *$ e para o Sorriso Total, ou seja, somatório dos três tipos de sorriso) obteve-se $\mathrm{F}=5,547(\mathrm{p}=0,011)$.

As comparações que se mostraram estatisticamente significativas são aquelas feitas do Sorriso Semi-aberto entre Colégio e Semi-internato; do Sorriso Fechado e Aberto entre Colégio e internato e de Sorriso Fechado, Semi-Aberto e Aberto entre Semi-internato e internato. No Sorriso Total as comparações estatisticamente significativas são entre Colégio e Semi-internato e entre Colégio e Internato. Estes dados podem significar que o grupo de adolescentes do Colégio assemelha-se mais ao grupo de adolescentes de Semiinternato e difere, portanto do grupo do internato. pois apenas no que tange ao tipo de sorriso SemiAberto os indices do Colégio foram similares aos do internato; já os índices do Sorriso Fechado e Sorriso Aberto tiveram valores que diferiram es- tatisticamente entre si. Os grupos do Semi-internato e do Internato diferiram entre si nos três tipos de sorriso.

\section{CONCLUSÃO}

AMBROSE (1961) fala sobre os efeitos eletrizantes do sorriso do bebê sobre o comportamento da mãe. A mãe torna-se mais receptiva e caso irritada ou cansada poderá se sentir desarmada e recompensada pelo sorriso do bebê. O sorriso. segundo BOWLBY (1984), ateia de tal maneira a mãe que. no futuro. ela estará pronta a responder com presteza aos menores sinais do filho, favorecendo a sobrevivência e bem estar da criança.

Os resultados dos dois experimentos indicaram que. provavelmente. em ambientes onde as condições familiares são mantidas. o desenvolvimento do vínculo afetivo também poderá estar presente o que determinará um maior grau de satisfação e bem-estar com a vida. Esta satisfação e bem-estar poderão ser quantificados através de ín- 
dices de sorriso. As instituições que isolam as crianças e adolescentes do convívio familiar prejudicam fortemente o seu desenvolvimento afetivo e sua felicidade. Os baixos índices de sorriso observados nas crianças institucionalizadas e nos adolescentes internos mostraram claramente este fato.

Aqueles que defendem abrigos para crianças abandonadas - limpos. com boa alimentação, bom vestuário, com brinquedos - esquecem de verificar quais são as variaveis essenciais para o desenvolvimento adequado do ser humano. Seu sorriso, sua felicidade, devem ser os indicadores apropriados para avaliar se o modelo proposto vem suprir suas carências. As experiências atuais com casas lares, casas de apoio, lar substituto, adoção, guarda, semi-liberdade. liberdade assistida, vêm romper com uma tradição de um século onde a medida conveniente adotada pela sociedade e pelos poderes instituidos era a de isolar, em grandes orfanatos, as crianças e adolescentes abandonadas, órfãos e infratores. Orfanatos estes que produziram, como é do conhecimento de todos. um contingente enorme de adolescentes desajustados e incapazes de inserirem-se na sociedade, pois viveram à margem desta e sofrendo as conseqüências do modelo perverso e capaz de gerar delinqüentes em massa (GOMIDE, 1990).

Pesquisas envolvendo sorriso, riso. alegria, tristeza e medo em crianças e adolescentes, institucionalizados ou não, poderão servir para que os especialistas da área social e os legisladores, politicos e govrnantes tenham elementos efetivos para basear suas ações. Modelos pedagógicos e educativos que propiciem uma diminuição da felicidade e um aumento do estado de tristeza, por conseguinte, deverão ser reconsiderados. A Ciência Psicológica e a Pedagógica, definitivamente, estão convencidas de que para haver mudanças de comportamento, introjeção de valores morais e regras sociais é preciso que o sujeito aprendiz esteja submetido a uma situação agradável, onde a aprendizagem seja mediada pela afetividade. Puniçoes, com reclusão, apenas atendem ao anseio popular de afastar o infrator, ou o menino de rua pedinte, do convívio social. O retorno destes indivíduos à sociedade, após um período de internamento, é desastrosa. São crianças e adolescentes que além de despreparados para a interação social trazem consigo um sentimento de amargura, desconfiança e desafeto para com os membros da sociedade.

O ser humano necessita do afeto e do afago de seus semelhantes para desenvolver-se em harmonia, sem agressividade. A agressividade do homem advém principalmente das condições adversas a que é submetido. Produzir modelos pedagógicos sem reproduzir condições familiares e de convivio social é optar por um modelo equivocado incompetente e fadado ao fracasso.

\section{A GRADECIMENTOS}

A autora agradece a colaboração dos alunos da disciplina de Pesquisa e Técnica de Coleta de Dados de 1992: Betti Welzel, Cláudia Moreira, Cristina Ferting, Cristina Muniz, Jaqueline Becker, Juliane Varaschir, Laisa Webwr, Lenara Leticia Galassini, Marcos Henrique Hens, Regiane Fernandes e Silvia Paula Rigoni que coletaram os dados do Experimento I.

A autora agradece a colaboração dos alunos da disciplina de Pesquisa e Técnica de Coleta de Dados de 1993: Ana Paula Pereira, Cintia Gofmann, Cyntia Mara Correa, Josilene Brodzinski, Luciene Borgorha da Silva, Sanah Abdullah, Valéria Pereira, que cotaram os dados do Experimento II.

\begin{abstract}
This work analyses the effects of institutionalization or family life on children's and yong adults' smiling behavior. Man owns a universal collection of expressive movements that allows communication despite lan uage and cultural barriers. Researchers on facial expression have verified that the smile is a powerful source of interpersonal gratification and is related to the emotional state of joy. Orphanages, slums and family environment vary in degree and frequency of emitted and correspondend smiles. Two experiments were carried out to investigate the abovementioned hypothesis. Exp I registered smiles in children of both sexes, ages between 5 and 10 years old, coming from an orphanage, a slum and a middle-class neighborhood. Exp 11 observed young adults from 14 to 21 years old, male, derived from an orphanage for law-breakers, a boarding school for law-breakers and a regular high school. The subjects were observed in playing activities. It was clearly verified that children and adolescents raised in institutions smile less than those brought up in freedom, even when in precarious social conditions as in slums. This research indicates that institutions that isolate children and adolescents from their families strongly harm their emotional development and their happiness.
\end{abstract}

Key-words: smile, child, young adult, institutionalization. 


\section{REFERÊNCIAS BIBLIOGRÁFICAS}

AMBROSE, J. A. The development of the smiling response in early infancy. In: FOSS, B. M. ed. Determinants of in Infant Behavior v. 1, London, Methuen, 1961.

BOWLBY, J. Apego. São Paulo, Martins Fontes, 1984.

BLURTON JONES, N. G. Estudos ecológicos do comportamento da criança. São Paulo, Pioneira Editora, 1972.

BUGENTAL, D. E.; KASWAN, J. W.; LOVE, L. R. Perception of contradictory meanings conveyed vy verbal an nonverbal channels. $J$. Pers. Soe. Psycho., 16: 647-655, 1970.

BRANNIGAN, C. R.; HUMPHRIES, D. A. Comportamento não-verbal: um meio de comunicação. In: JONES, N. B. ed. Estudos etológicos do comportamento da criança. SãoPaulo, Pioneira, 1972.

CHEVALIER-SKOLNIKOFF, S. Facial expression of emotion in non-human primates. In: EKMANN, P. ed. Darwin and facial expression. New York, Academ ic Press, 1973.

CHEYNE, J. A. Development of forms and functions of smilling in pre-schoolers. Child Dev., 47: 820-823, 1976.

DARWIN, C. The expression of emotions in man and animais. London, Murray, 1872.

EIBSFELDT, I. E. Amor e ódio. Amadora, Portugal, Bertrand, 1970.

FAGUNDES, A. J. Definição e análise de respostas de sorrir em situação de leitura de textos humorísticos. São Paulo, 1976. [Dissertação de Mestrado - instituto de TecnologiaUSP].
GEWIRTZ, J. L. The course of infantsmiling in four childrearing environments in Israel. In: FOSS, B. M. ed. Determinants of infant behavior, v. 3, London, Methuen, 1965.

GOFFMAN, E. Cender advertisements. Nova York, Harper \& Row, 1979.

GOMIDE, P. I. C. Menor infrator: a caminho de um novo tempo. Curitiba, Juruá, 1990.

HALBERSTADT, A. G.; SAITTA, M. B. Gender nonverbal behaviour and perceived dominance: a test of teory. J. Pers. Soc. Psychol., 53 (2): 252-272, 1987.

KRAUT, R. E. Verbal and nonverbal cues in the perception of lying. J. Pers. Soc. Psychol., 36: 380-391, 1978.

LORENZ, K. Agressão. Portugal, Martins Fontes, 1966.

OTTA, E.; SARRA, S. Um estudo sobre o sorriso e o riso em crianças de quatro e cinco anos. Psicologia USP., 1: 13-94, 1989.

OTTA, E.; OBARA, C.; BONILHA, R.; AKAMINE, C.; BORTOLETTO, A. C.; PEDRAZZOLI NETO, M. Sorriso em bebês: reação à face humana e vários tipos de degradações deste estimulo. Rev. Bras. Cresc. Desenv. Hum., 2 (2): 117-125,1992.

OTTA, E. O sorriso e seus significados. Petrópolis, Vozes, 1994.

SPITZ, R. A. O primeiro ano de vida. São Paulo, Martins Fontes, 1991.

VAN HOOF, J. A. A comparative approach to the phylogeny of laughter and smilling. In: HINDE, R. ed. Non verbal communication. Cambridge University Press, 1972.

recebido em: 24/05/95 aprovado em: 12/10/95 